\title{
Radiopharmaceutical Research and Production in Brazil: A 30-Year History of Participation in the Nuclear Medicine Scenario
}

\author{
Ralph Santos-Oliveira ${ }^{1}$ and Leila Jorge Antunes ${ }^{2}$ \\ ${ }^{I}$ Radiopharmacy Committee, Brazilian Pharmacopoeia, Rio de Janeiro, Brazil; and ${ }^{2}$ Radiopharmaceuticals Division, Nuclear \\ Engineering Institute, Rio de Janeiro, Brazil
}

This article describes the 30-y history of nuclear medicine in Brazil, including reactors, production of radiopharmaceuticals, and trends.

Key Words: nuclear engineering; production; radiopharmaceuticals; radiopharmacy; trend

J Nucl Med Technol 2011; 39:237-239

DOI: 10.2967/jnmt.111.088450

$\mathbf{T}$ he Comissão Nacional de Energia Nuclear (National Commission for Nuclear Energy), or CNEN, was created in 1956 (decree 40.110 of October 10, 1956) to be responsible for all nuclear activities in Brazil. Later, CNEN was reorganized and its responsibilities were established by law $4118 / 62$, with alterations determined by laws $6189 / 74$ and 7781/89. Thereafter, CNEN became the body in charge of regulating, licensing, and controlling nuclear energy use, and nuclear electric generation was transferred to the energy government sector. CNEN is also responsible for research and development and the production of radioisotopes.

The IEA-R1 (Instituto de Energia Atômica Reator 1), considered the most important Brazilian research reactor, is the oldest in the southern hemisphere. Located at the Instituto de Pesquisas Energéticas e Nucleares (Nuclear and Energetic Research Institute), or IPEN, on the campus of São Paulo University, its construction began in 1956 within the scope of the U.S. program Atoms for Peace. The reactor reached criticality for the first time on September 16, 1957. Although designed to operate at $5 \mathrm{MW}$, from 1957 until 1961 the operation of the reactor was mainly for commissioning tests and nuclear physics experiments. The reactor was operating on weekdays, less than $8 \mathrm{~h}$ a day, with a power level between

\footnotetext{
Received Feb. 7, 2011; revision accepted Mar. 29, 2011.

For correspondence or reprints contact: Ralph Santos-Oliveira, Radiopharmacy Committee, Brazilian Pharmacopoeia, Rua Hélio de Almeida 75, Ilha do Fundão, Rio de Janeiro, Brazil.

E-mail:roliveira@ien.gov.br or uffista@gmail.com

Published online Jul. 27, 2011.

COPYRIGHT @ 2011 by the Society of Nuclear Medicine, Inc.
}

$200 \mathrm{~kW}$ and $2 \mathrm{MW}$. In 1961, a program was established to produce ${ }^{131} \mathrm{I}$, and the reactor began to be operated at a constant power of $2 \mathrm{MW}, 8 \mathrm{~h}$ per day and $5 \mathrm{~d}$ per week $(1,2)$. In 1995 , a program was established to start the immediate production of ${ }^{153} \mathrm{Sm}$ and to prepare the reactor to produce ${ }^{99} \mathrm{Mo}$. As result of this decision, the operating schedule was changed to $64 \mathrm{~h}$ per week, from Monday through Wednesday, keeping the reactor power at $2 \mathrm{MW}$. Some modifications were introduced to comply with the new national legislation in order to operate continuously during $120 \mathrm{~h}$ per week at 5 MW. The burnup rate, which is currently 240 MW day (MWD), is expected to increase to 1,100 MWD.

The IPR-R1 (Instituto de Pesquisas Radioativas Reator 1), a 250-kW Training Research Isotope General Atomic (TRIGA) reactor operating at the Centro de Desenvolvimento de Tecnologia Nuclear (Nuclear Technology Development Centre), or CDTN, on the campus of the Federal University of Minas Gerais in the city of Belo Horizonte, is used mainly for research. It was the second Brazilian research reactor, with its first criticality reached in November 1960 . This reactor operates $4 \mathrm{~h}$ per day, $5 \mathrm{~d}$ per week, and 40 wk per year. The integrated burnup of the reactor from its first criticality until now has been about 130 MWD $(3,4)$. Because of the low nominal power, except for aging concerns, spent fuel is far from being a problem. The first fuel assembly replacement of the reactor was not expected to occur until 2010.

The third Brazilian research reactor is the Argonauta, located at the Instituto de Engenharia Nuclear (Nuclear Engineering Institute), or IEN, on the campus of the Federal University of Rio de Janeiro. Argonauta's first criticality was reached in February 1965. This reactor can operate at a maximum power of $1 \mathrm{~kW}$ during an hour or $500 \mathrm{~W}$ continuously. It is usually operated in the range of $170-340 \mathrm{~W}$ (5). Its accumulated burnup, since the first criticality, is about 0.25 MWD. As in the case of IPR-R1, because of the low nominal power, storage of spent fuel is not a problem. It is used mainly for training purposes, research, and sample irradiation.

The use of radioisotopes in research occurs mainly at CNEN's research institutes (IPEN, IEN, and CDTN), but also other research centers and universities use radioactive sources. The research is diverse, including nuclear physics, biol- 
ogy, agriculture, health, hydrology, and the environment. Small sources of ${ }^{3} \mathrm{H},{ }^{14} \mathrm{C},{ }^{22} \mathrm{Na},{ }^{55} \mathrm{Fe},{ }^{63} \mathrm{Ni},{ }^{125} \mathrm{I},{ }^{226} \mathrm{Ra},{ }^{35} \mathrm{~S}$, and ${ }^{32} \mathrm{P}$ are used.

\section{PRODUCTION OF RADIOPHARMACEUTICALS}

Radioisotopes for medical uses are produced in IPEN at the Cyclotron Accelerators Center and the Research Reactor Center. These radioisotopes, together with other imported ones, are processed at the Radiopharmacy Center under the requisites of the ISO 9002 standards and distributed just in time to hospitals throughout the country caring for more than 2.3 million patients per year. A total of about $640 \mathrm{TBq}$ of ${ }^{18} \mathrm{~F},{ }^{67} \mathrm{Ga},{ }^{123} \mathrm{I},{ }^{131} \mathrm{I},{ }^{99} \mathrm{Mo},{ }^{153} \mathrm{Sm},{ }^{35} \mathrm{~S}$, ${ }^{32} \mathrm{P}$, and ${ }^{51} \mathrm{Cr}$ compounds are processed annually at IPEN.

Since 1974, IEN has had a CV-28 cyclotron, which was originally used in physics and radioisotope production research and now is used mainly in the production of radiopharmaceuticals for diagnostic examinations. In 1998 the Institute adopted the Karlsruhe Iodine Production System (KIPROS) for the production of ${ }^{123} \mathrm{I}(6)$. This production routine provides conditions for labeling special molecules. The first one was ${ }^{123}$ I-labeled metaiodobenzylguanidine (MIBG), whose main application is in cardiology.

In 2000, one ${ }^{18} \mathrm{~F}$-FDG production unit from Ion Beam Applications was imported and connected to IEN's CV-28 cyclotron. Use of this unit began on an experimental basis, producing ${ }^{18} \mathrm{~F}$. Samples of FDG labeled with ${ }^{18} \mathrm{~F}$, which was considered the newest and most innovative technology in nuclear medicine $(7,8)$, started to be sent to hospitals in Rio de Janeiro. Because of the short life, only $1.8 \mathrm{~h}$, this radiopharmaceutical must be produced as near as possible to the application site (within $\sim 200 \mathrm{~km}$ ).

In 2003, after the installation of the RDS-111 cyclotron (CTI/Siemens), IEN stepped up the production of ${ }^{18} \mathrm{~F}$ and, consequently, ${ }^{18} \mathrm{~F}$-FDG. This system is recognized worldwide for its reliability and simplicity of operation. With the RDS111 , IEN was able to produce ${ }^{18} \mathrm{~F}-\mathrm{FDG}$ in 2 independent ways, with different installations, 1 of them as a backup. The redundancy was created to guarantee the delivery process.

The CDTN inaugurated its radiopharmaceutical production unit in the first half of $2008(9,10)$ and started the pilot production of ${ }^{18}$ F-FDG in the second half of the year, reaching commercial production of this radiopharmaceutical in 2009.

\section{PET Radiopharmaceuticals}

PET is a complex and high-cost nuclear medicine technology. The diffusion of PET in Brazil is recent and still limited, but the fall of the federal monopoly on the production of radiopharmaceuticals in 2006 triggered a movement to multiply the number of cyclotron installations and the purchase of PET scanners, especially by the private health sector. The resulting increase in demand has placed pressure on the Brazilian National Health System to incorporate this type of examination into the reimbursement tables, requiring evidence-based updated appraisals to support the decision-making processes.
In the last decade, ${ }^{18} \mathrm{~F}-\mathrm{FDG}$ has become a breakthrough in nuclear medicine (9). Associated with new-generation equipment for PET or SPECT, ${ }^{18} \mathrm{~F}-\mathrm{FDG}$ is now widely used in oncology, visualizing and distinguishing malignant from benign tumors as well as distinguishing primary tumors from metastases. In cardiology, one of its applications is assessing the level of damage to the heart that has undergone a cardiovascular accident. In neurology, PET technology can be applied to diagnose Parkinson, Alzheimer, and Tourette diseases and to visualize brain damage caused by drug consumption. PET technology began in 1981, when the first PET scanner became available. Currently, there are more than 500 centers operating mainly in the United States, Europe, and Japan. In the specific case of Brazil, the tropical diseases are an open field for research, with unpublished applications.

\section{I-MIBG Radiopharmaceutical}

MIBG is labeled at the IEN radiopharmacy laboratory using ultrapure ${ }^{123}$ I produced at the KIPROS system. The ${ }^{123} \mathrm{I}$ is obtained by bombardment of a ${ }^{124} \mathrm{Xe}$ target with a $24-\mathrm{MeV}, 20-\mu \mathrm{A}$ proton beam in the CV-28 cyclotron. The labeling method is based on a nucleophilic substitution in an MIBG molecule. In order for the product to be used as a diagnostic agent, the radiochemical purity must be as high as $97 \%$. Because of a half-life of only $13.2 \mathrm{~h},{ }^{123} \mathrm{I}-\mathrm{MIBG}$ allows the diagnosis of heart diseases and tumors. However, ${ }^{131} \mathrm{I}-\mathrm{MIBG}$, because of a longer half-life $(8 \mathrm{~d})$, is more suitable for higher-dose treatment of tumors. With the production of ultrapure ${ }^{123} \mathrm{I}$, IEN follows a worldwide trend to make short-half-life radioisotopes available for examinations and therapy.

\section{DATA AND TRENDS}

In terms of sales, Brazil is a major player in the radiopharmaceutical market despite considerable barriers to production and reimbursement. In 2009, Brazil sold almost 70 million Reais of ${ }^{18}$ F-FDG. Converting this value to U.S. dollars, sales of ${ }^{18} \mathrm{~F}-\mathrm{FDG}$ in Brazil were approximately $\$ 35$ million, compared with U.S. sales of $\$ 522$ million in 2009. Despite having only 2 PET radiopharmaceutical facilities, Brazilian production was equal to $6.7 \%$ of the U.S. production from more than 30 PET facilities. This is an impressive feat. However, it is not clear that these facilities can continue to expand production to meet the growing demand for imaging using radiopharmaceuticals. The reliance on just 2 high-volume facilities for the entire national production of PET radiopharmaceuticals suggests an urgent need to increase the number of production facilities in Brazil.

\section{ACKNOWLEDGMENT}

This study was supported by FAPERJ and CNPq. No potential conflict of interest relevant to this article was reported. 


\section{REFERENCES}

1. Centro de reator de pesquisa: utilização do reator. Instituto de Pesquisas Energéticas e Nucleares Web site. Available at https://www.ipen.br/sitio/?idm=251. Accessed May 6, 2011.

2. Comissão Nacional de Energia Nuclear. National Report of Brazil for the Joint Convention on the Safety of Spent Fuel Management and on the Safety of Radioactive Waste Management. Rio de Janeiro, Brazil: Comissão Nacional de Energia Nuclear; 2006:97.

3. de Tello CCO, Grossi PA, Mesquita AZ. IPR-R1 TRIGA Research Reactor decommissioning: preliminary plan. In: Proceedings of the 2007 International Nuclear Atlantic Conference; Santos, São Paulo, Brazil; September 30-October 5, 2007.

4. Grossi PA, de Tello CCO, Mesquita AZ. IPR-R1 TRIGA Research Reactor decommissioning plan. Presented at the 12th International Congress of the International Radiation Protection Association, 2008. Available at: http://www. irpa12.org.ar/index.php. Accessed May 9, 2011.

5. Instituto de Engenharia Nuclear Web page on the history of the Argonauta reactor. Available at: http://www.ien.gov.br/oinstituto/instalacoes/serea/argonauta/ historico_01.htm. Accessed May 9, 2011.
6. Instituto de Engenharia Nuclear Web site. Progress Report 2001-2002: Radiopharmaceuticals. Available at: http://www.ien.gov.br/public/progreport_2001_2002/ 04\%20DIRA\%20rev01.pdf. Accessed May 9, 2011.

7. Instituto de Engenharia Nuclear Web page on radiopharmaceutical production. Available at: http://www.ien.gov.br/ingles/fields/radiopharm.php. Accessed May 9, 2011.

8. Comissão Nacional de Energia Nuclear Web site. Relatório de Gestão 2008. Available at: http://www.cnen.gov.br/acnen/relatorios/rel-gestao-2008.pdf. Accessed May 9, 2011.

9. Vasconcellos MBA, Saiki M. Radiochemistry teaching and research activities in Brazil. J Rad Nucl Chem. 2006;270:263-267.

10. Comissão Nacional de Energia Nuclear. National Report of Brazil for the Joint Convention on the Safety of Spent Fuel Management and on the Safety of Radioactive Waste Management. Rio de Janeiro, Brazil: Comissão Nacional de Energia Nuclear; 2008:128.

11. Santos-Oliveira R, Antunes LJ, Albernaz MS, Bordim JA, Smith SW. Survey on radiopharmaceuticals in Brazil: trends and analysis. Curr Radiopharm. 2010;3: 304-307. 